\title{
SACRIFICIAL SUPPORT FIXTURE OPTIMISATION FOR THE CNC RAPID MACHINING OF MEDICAL PARTS WITH THIN ENDS
}

\begin{abstract}
Summary
The purpose of this paper is to develop a methodology for optimising the shape of automated sacrificial support fixture (SSF) design, so as to machine a part with thin ends (like the hip joint) using a rapid machining process. A sacrificial support fixture is created at the ends of the part to give support to the part during machining. Finite element analysis (FEA) is used to optimise the shape of sacrificial support fixture for the machining of a part via computer numerical control rapid prototyping (CNC-RP). The research work proves that the optimised design of a sacrificial support fixture has been extremely flexible in securing a variety of intricate parts having thin ends in the computer numerical control rapid prototyping machining. For rapid machining, a tapered support is best suited for the part with thin ends. The limitation of the optimised sacrificial support fixture, designed for an intricate part, is that it is applicable only to CNC machining with the four axis rotational setup.
\end{abstract}

Key words: $\quad$ rapid machining, computer numerical control, design optimisation, finite element analysis, rapid prototyping.

\section{Introduction}

Computer numerical control rapid prototyping (CNC-RP) combines the $\mathrm{CNC}$ machining with the RP methods to create a functional part in an automated manner using a variety of materials $[1,2]$. CNC-RP is a subtractive rapid prototyping process. CNC machining consists of three axes, i.e. the $\mathrm{X}$-axis, the $\mathrm{Y}$-axis, and the $\mathrm{Z}$-axis. The machining of a workpiece takes place along the Z-axis. In order to turn CNC machining into a rapid prototyping process, an extra axis of rotation is provided using the indexer so that the tool can remove the material from all directions by simultaneous milling and turning [3, 4]. Rapid planning and rapid tooling are important factors in turning the CNC machining into a CNC-RP process [3, 5].

When conventional methods of fixturing, such as vises, clams, and v-blocks, are used, it is extremely difficult for a part to rotate about the axis of rotation. During machining, a complex manual setup is required to hold an intricate part using traditional fixtures; this prevents $\mathrm{CNC}-\mathrm{RP}$ to be considered as a rapid machining technique $[5,6]$. 
In CNC-RP, instead of adding material to the part, sacrificial supports are added to the CAD model before the tool path planning and are subsequently created along with other part features during machining [7]. A sacrificial support fixture (SSF) is applied as a small feature at the end of the parts which are created parallel to the axis of rotation, as shown in Fig. (2). In the previous research work, the SSF used had a cylindrical shape. The SSF served as a traditional fixture and was used for the CNC-RP processes only. The SSF, which can be used for providing a completely automated rapid machining system, is exceedingly flexible in securing a vast array of intricate parts [8].

The generalized methodology of machining a part with SSFs using CNC-RP is shown in Fig. (1) [7, 9]. According to Boonsuk and Frank, the cylindrical supports are robust in design, easy to place, and have low deflection, but they can be used for giving support to the part with thick ends only as in the case shown in Fig (1a) [7]. Cylindrical supports cannot be used for parts with thin ends, such as the hip joint, as these parts have very small contact area, as shown in Fig. (1b). Therefore, the part with thin ends, such as the hip bone, needs the supports to be made in a very small diameter. However, a reduction in the diameter of the support to a very small value will entail an additional problem of the part failure due to bending and torsion during machining. A cylindrical shape of an SSF cannot be a desired shape for a part with thin ends being subjected to the CNC-RP machining. Previous research addressed this issue in the design of optimal shapes of SSFs for each of geometries of parts with thin ends [7]. This study focuses on the design and analysis of different shapes of SSFs for different geometries of parts with thin ends. In this paper, finite element analysis (FEA) of the design parameters of the SSF is carried out for different shapes to get the desired shape of the SSF for each of the geometries of the part with thin ends. A case study into permissible deflection and normal stresses of a medical part, e.g. the hip joint, is done using FEA.

The major problem during the machining of a part with thin ends, e.g. the hip joint, using CNC-RP is to ascertain which SSF shape combination will work for the part so that the total deflection should be below the permissible value [7]. The structural characteristics of the desired SSF for a part with thin ends are important as the CNC-RP process involves cutting forces and the designed SSF should not allow the total deflection and normal stresses to exceed the allowable deflections and normal stresses produced in the part during machining. To date, the research work presented in this paper has developed an automated SSF for each of the geometries of parts with thin ends. Subsequently, a finite element analysis is done to find the total deflection and normal stresses developed in the part using SSFs. This paper presents an approach to resolving the complex problem of automatic determination of SSF combinations that will work for the parts with thin ends. The challenge is that the SSF having a very small diameter should not bend or deflect while the part with thin ends is being machined using CNC-RP. Another challenge is that the SSF with a small diameter must work for any geometry of the CAD model with thin ends without human intervention. This methodology attempts to simplify this complicated problem of determining what SSF shape works best for the intricate parts with thin ends being machined by CNC-RP.

The section dealing with the implementation of the proposed method will provide a case study of creating the design of an SSF for an intricate medical part with thin ends, e.g. the hip bone $[10,11]$. The hip joint part made of stainless steel $316 \mathrm{~L}$ is machined in the laboratory using CNC-RP and an automated SSF. 


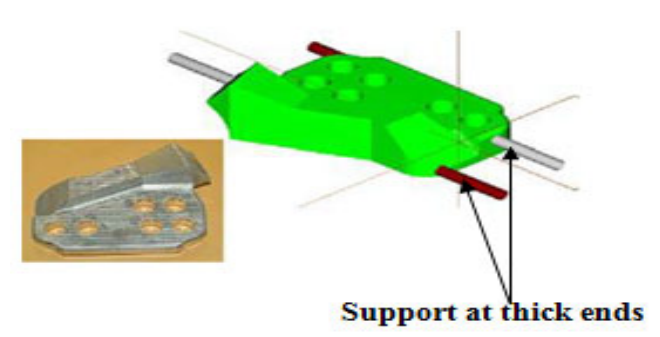

(a)

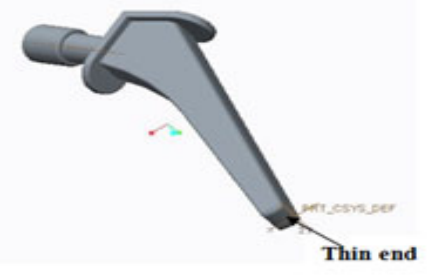

(b)

Fig. 1 (a) Alignment box with SSFs at thick ends [4] (b) Hip joint with a thin end.

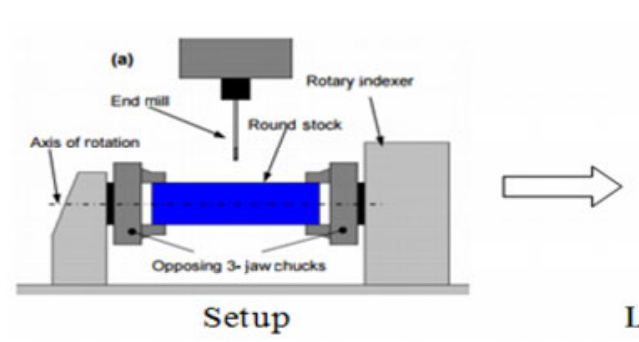

Left support section and Right support section

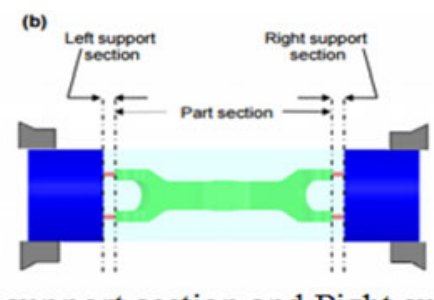

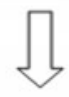

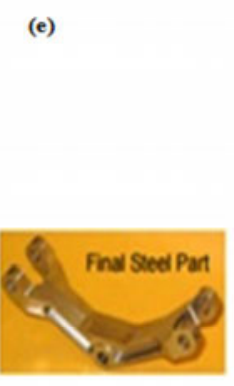

Finished part

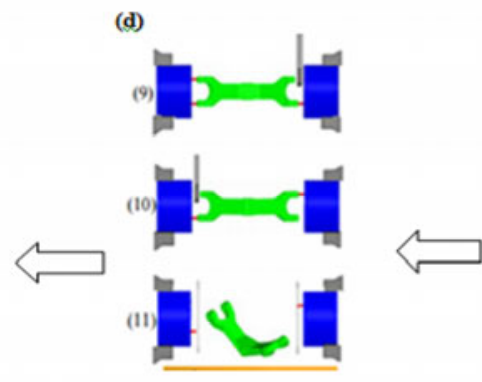

Support section machining (c)

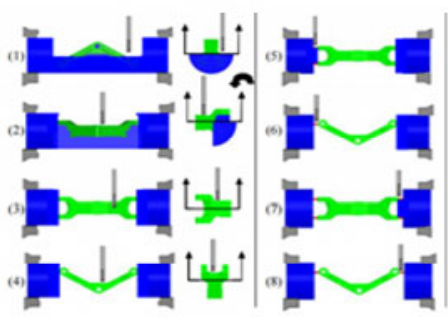

Part section machining

Fig. 2 Generalised standard process for the development and fabrication of an SSF [7].

\section{Literature Review}

A new concept of rapid planning of computer numerical control (CNC) machining is presented by Matthew et al. in 2004 [4]. The authors of the study developed a concept of SSF design for $\mathrm{CNC}$ machining. They used $2^{1 / 2}-\mathrm{D}$ tool path orientation about the axis of rotation and the concept of visibility of the part using the four axis $\mathrm{CNC}$ machining. They concluded that the SSF design greatly reduced the cost in short production runs or batch processing of the part.

The support structures are created and implemented as small features parallel to the axis of rotation of the part during machining. The SSFs are created automatically, and they are used as a fixture [7]. Machining of various parts was done using only cylindrical SSFs. They did not work on the parts having very thin ends because the cylindrical SSF requires a very small diameter support.

SSF is a very reliable method of fixing and should be used for small batches of parts, for rapid prototyping with $\mathrm{CNC}$ machining, and for parts with irregular shapes provided that the results of the cost-effectiveness of the process are satisfactory. [12]. The present study analyses the use of this method as a function of the number of parts to be produced, the number of features on the part, the material removed to the final part volume ratio, and the basic part geometry. 
Research work on the planning of the fourth axis in CNC machining was done to provide complete surface coverage while machining a part using CNC [8]. The researchers worked on the issues such as multiple setup operations and stock material management. They investigated the algorithm for improving the efficiency and reliability of multiple layer-based removal steps for rapid machining.

Several researchers studied the effect of surface finish of the machined part and they concluded that it is a function of the cutting tool used for machining [13] and of the SSF used for holding the part during the process [14]. The flat and ball nose end mills can be used for better surface finish through rapid machining. Chattering of the end milling tool during machining was studied by using finite element analysis modelling and stability analysis of chatter in end milling [15].

In 2015, Osman Zahid et al. found out that the capability of CNC for the rapid machining operation can be improved by using dissimilar end mill tools for finishing. They introduced a new layer removal methodology in which an indexing device is used to clamp the workpiece and an SSF to hold the part during rapid machining [16].

In 2017, Osman Zahid et al. proposed rapid process planning in CNC machining for rapid manufacturing applications. The authors of the study developed a customized coding and connected it with the CAD software. They built a customized programme for designing a machining process of all kinds of parts to reduce the process planning time and the process planning complexity. Using SSFs and the customized program, they fabricated a number of parts, such as a femur bone, a toothbrush stick, and a propeller [3].

In 2007 and 2010, Frank et al. investigated the machine setup planning, the SSF design, and the tool path planning using an advanced geometric algorithm and interfacing it with $\mathrm{CAD} / \mathrm{CAM}$ to allow the automatic NC code generation directly from the CAD model $[17,18]$.

The finite element analysis is a widely used and recognized method for determining optimal process parameters, according to the work done by various researchers [19-21, 36]. In the studies [22-25], FEA plays a very vital role in finding out various types of deflections and stresses produced in a part during machining.

\section{Methodology}

Previous research work was focused on designing SSFs of cylindrical shape for parts with thick ends to be machined by CNC-RP [7]. The parts with thin ends cannot be machined using CNC-RP if the same approach of cylindrical SSFs is adopted. Therefore, there is a need to optimise the shape and the design parameters of SSFs for the CNC-RP machining of a part with thin ends [26]. Optimisation of the design of SSFs intended for parts with thin ends requires a comprehensive analysis and design iterations/simulations [27, 28]. The technical challenge in optimising the shape and the design of SSFs intended for parts with thin ends is to reduce the diameter of the SSF to obtain a small contact area of the part such that it could satisfy the maximum allowable deflection and normal stresses produced in the part during machining. The basic methodology for optimising the shape and the design of SSFs for parts with thin ends to be machined by CNC-RP will cover the following major necessary areas:

1 Finding the best shape of an SSF suited to the part with thin ends using FEA

2 Determination of the design parameters by means of FEA 
3 Using FEA, finding different combinations of shapes of SSFs designed for the part with thin ends intended for satisfying the maximum allowable deflection and normal stresses for the CNC-RP machining.

4 Comparison of different combinations of SSFs and identification of the one which is best suited to the part with thin ends.

\subsection{Material specifications and boundary conditions used for finite element analysis}

The mechanical properties of the material (Nandishwar steel) used for optimising the design of an SSF intended for parts with thin ends are given below; the Ansys 14.0 software was used in the optimisation performed by FEA. The research on the cutting force calculation using the finite element analysis of the parameters designed for the CNC-RP machining of a hip joint part with an innovative sacrificial support structure as a fixture was done by Ramteke in 2018 [29] and the same parameters are used here for the current study [29-31, 35, 37].

Material used- Stainless Steel 316L

Density $=8,000 \mathrm{Kg} / \mathrm{m}^{3}$

Modulus of elasticity $=2 \cdot 10^{9} \mathrm{~Pa}$

Poisson's ratio $=0.25$

Tensile yield strength $=205 \cdot 10^{6} \mathrm{~Pa}$

Tensile ultimate strength $=515 \cdot 10^{6} \mathrm{~Pa}$

Mesh size $=1.6 \mathrm{~mm}$

Force $=22 \mathrm{~N}$.

\subsection{Design parameters}

The current research work deals with the optimisation of the shape and the design parameters of an SSF intended for a part with thin ends; the optimisation is done using FEA for the minimum bending and torsional deflection for the $\mathrm{CNC}-\mathrm{RP}$ machining. Finding an optimal solution for the support design is very difficult since by varying one parameter of support, an effect on the other parameters is produced [7]. For example, by varying the size, i.e. the diameter of a support, the length of the support will be affected. The design parameters of the support will vary according to the shape of supports.

\section{Results and Discussions}

\subsection{Shape of a sacrificial support fixture intended for a part with thin ends}

Cylindrical SSFs are not applicable to the parts with thin ends as they require SSFs with a very small diameter which can withstand the force applied in the CNC-RP machining [7]. The research work in this paper defined two different shapes of SSFs designed for the part with thin ends, i.e. elliptical and tapered SSFs. As both the elliptical and tapered shapes have small diameters as compared to the cylindrical shape, these shapes can be used for an SSF intended for the parts with thin ends, as shown in Table 1. The diameter of support can be reduced to a very small value by using a tapered shape as per the requirement of contact area of thin ends of the part. In the tapered support, the diameter goes on increasing depending on the taper angle. The focus in the next section is on the taper angle required for a very small diameter of the tapered support which allows the maximum allowable deflections and stresses produced in the part; FEA is used to determine that. 
Table 1 Different shapes of SSFs.

\begin{tabular}{|c|c|c|c|c|}
\hline S/N & Shape of SSF & $\begin{array}{c}\text { Cylindrical } \\
\text { SSF(Boonsuk and } \\
\text { Frank, 2009) }\end{array}$ \\
\hline 1 & Elliptical SSF & Front view \\
\hline 3 & Tapered SSF & & Top view \\
\hline 2 & &
\end{tabular}

\subsection{Length to radius ratio for different shapes of sacrificial supports}

Supports are smaller than a part to be machined; thus, this research is based on the assumption that the deflection produced in the part is a result of the deflection produced in the supports. Different shapes of supports are created at the ends of the part. One end of a support is fixed to the part and the other end is fixed to the indexer. Supports are fixed on both ends. A force of $22 \mathrm{~N}$ is applied at the centre of the beam [29]. During the machining process, according to the theory of machining for a fixed end beam, two different types of deflections occur in a fixed end beam, i.e. deflection due to bending $\left(Y_{\mathrm{b}}\right)$ shown in Eq. (1) and deflection due to torsion $\left(\theta_{\mathrm{t}}\right)$ shown in Eq. (2) [7].

Maximum bending deflection with fixed ends is as shown in Eq. (1),

$$
\begin{aligned}
Y_{b} & =\frac{F \cdot L^{3}}{192 \cdot E \cdot I} \\
\theta_{t} & =\frac{T \cdot L}{4 \cdot J \cdot G}
\end{aligned}
$$

where, $I=\left(\pi \cdot D^{4}\right) / 64, T=F \cdot L$ and $J=\left(\pi \cdot D^{4}\right) / 32$.

$T$ is the torque applied due to the force $F$ in (N), $L$ is the length in (mm), $J$ is the polar moment of inertia in $\left(\mathrm{m}^{4}\right), \mathrm{G}$ is the modulus of rigidity in $(\mathrm{Pa}), D$ is the diameter of the beam in $(\mathrm{mm}), E$ is the modulus of elasticity in $(\mathrm{Pa})$, and $I$ is the moment of inertia in $\left(\mathrm{kg} \cdot \mathrm{m}^{2}\right)$.

The length to radius ratio $(L / R)$ calculated for a cylindrical SSF designed for a part with thick ends is not applicable here [7]. So, here, the aim is the design of $L / R$ ratios for cylindrical, elliptical, and tapered SSFs intended for parts with thin ends. For determining the $L / R$ ratio for different shapes of SSFs, the radius of support is kept constant and the length is variable. The supports are fixed at both ends; thus the part can be considered as an 
indeterminate fixed end beam model, as shown in Fig (3). After applying a force of $22 \mathrm{~N}$ at the middle of the beam, the maximum bending and the maximum tensional deflection in the beam are found [37].
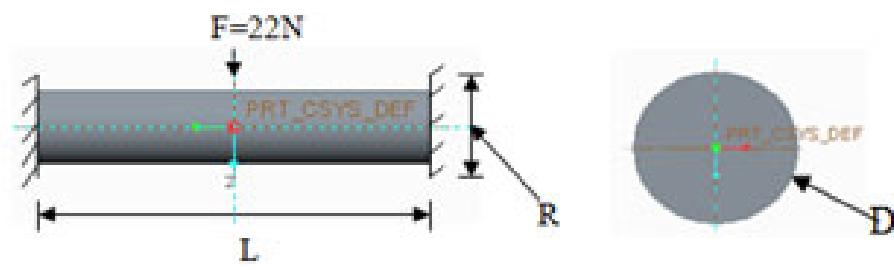

Fig. 3 Cylindrical support.

After taking a number of iterations with different $L / R$ ratios for different shapes using FEA, it is found that for cylindrical SSFs, the torsional deflection is maximum and the bending deflection is minimum with $L / R$ ratios of up to 13 ; after that limit, the bending deflection starts increasing and the torsional deflection starts decreasing, as illustrated in Fig (4a).

The $L / R$ ratio of 13 , having the torsional deflection of $57 \%$ of the total deflection and the bending deflection of $43 \%$, is shown in Fig (4b). We use two types of cylindrical supports, temporary and permanent [7]. For temporary supports, we use an $L / R$ ratio of 12 . For permanent supports, we use an $L / R$ ratio of 6 with torsional deflection of $73 \%$ of the total deflection and bending deflection of $28 \%$ of the total deflection, as shown in Fig (4b).

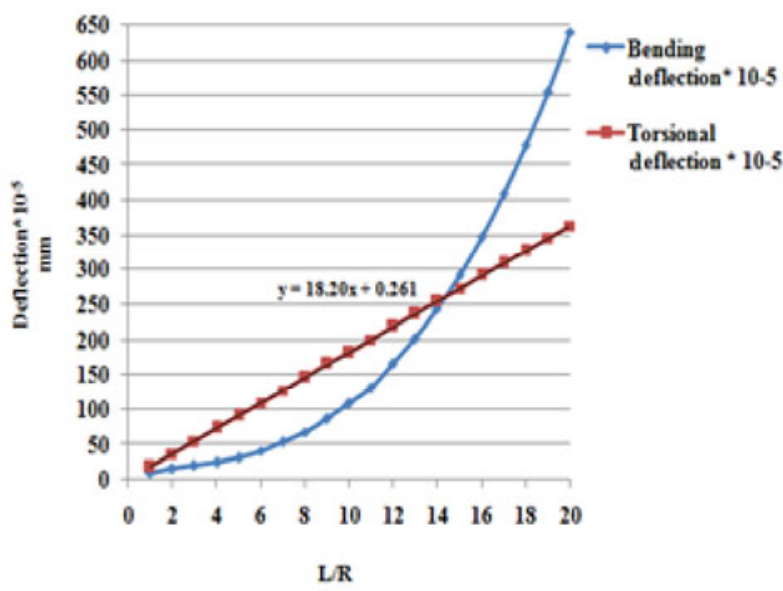

(a)

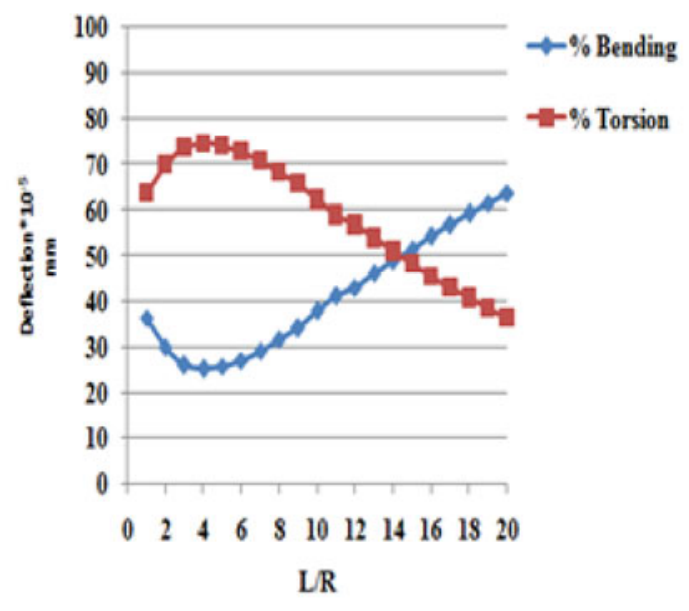

(b)

Fig. 4 (a) Different $L / R$ ratios versus deflection (b) percent deflection (\%) versus different $L / R$ ratios for cylindrical SSFs.

As for the elliptical SSF, an $L / R$ ratio of 12 was selected for the temporary support and an $L / R$ ratio of 6 for the permanent elliptical support as the bending deflection is smaller than the torsional deflection for $L / R$ ratios of up to 12 . For $L / R$ ratios greater than 12 , the bending deflection was found to be increasing and the torsional deflection started decreasing, as shown in Fig (5a). For the $L / R$ ratio of 6 , the torsional deflection is $76 \%$ of the total deflection and the bending deflection is $24 \%$ of the total deflection; for the $L / R$ ratio of 12 , the torsional deflection is $51.689 \%$ of the total deflection and the bending deflection is $49.61 \%$ of the total deflection, as shown in Fig (5b). The elliptical support has a major diameter and a minor diameter. This type of support is suitable for a part with thin ends. 


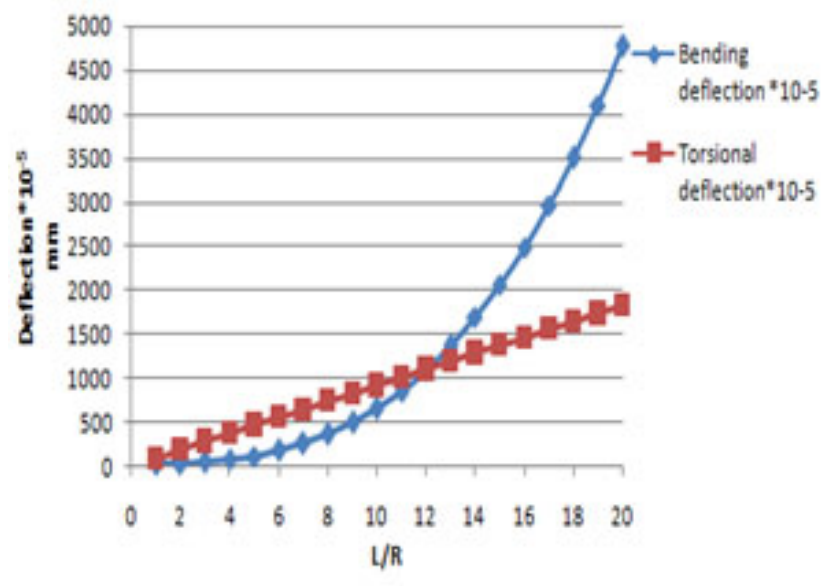

(a)

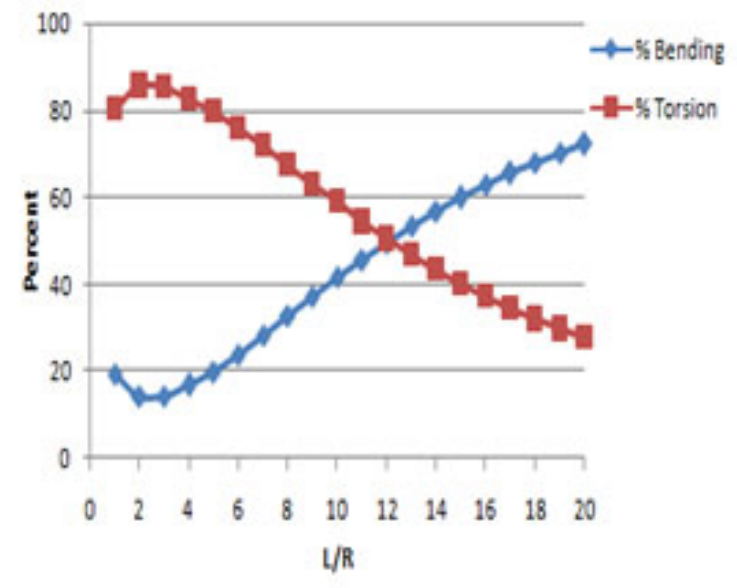

(b)

Fig. 5 (a) Different $L / R$ ratios versus deflection (b) percent deflection (\%) versus different $L / R$ ratios for elliptical SSFs.

For a tapered support, the deflection depends upon the angle " $\Theta$ " of the taper. Thus, for the tapered SSF, first, the value of " $\Theta$ " is calculated keeping the $L / R$ of 6 constant. Then, the finite element analysis is done on the part keeping the length to radius ratio $(L / R)$ of the support constant and varying the angle of the taper from 5 degrees to 30 degrees along with applying a force of $22 \mathrm{~N}$ at the middle. The results obtained from FEA show that with a reduction in the value of $\Theta$ from 30 to 5 degrees, the bending deflection starts increasing, which will result in an increase in the total deflection. For the tapered SSF, the value of $\Theta$ is selected to be 30 degrees because the bending deflection is negligible compared to the torsional deflection, as illustrated in Fig (6), although the values of both the bending and the torsional deflection are very small.

For the tapered SSF, the current approach is to use an $L / R$ ratio of 6 for a permanent support. The tapered SSF has only torsional deflection and the bending deflection is negligible, as shown in Fig (7a). For the $L / R$ ratio of 6 , the torsional deflection is almost $98 \%$ of the total deflection and the bending deflection is $2.2253 \%$ of the total deflection, as shown in Fig (7b). For the temporary tapered support, an $L / R$ of 12 having a small value of torsional deflection and the smallest value of bending deflection is selected, see Fig (7a). For the $L / R$ ratio of 12 , the torsional deflection is $99.02 \%$ of the total deflection and the bending deflection is $0.971 \%$ of the total deflection, as shown in Fig (7b).

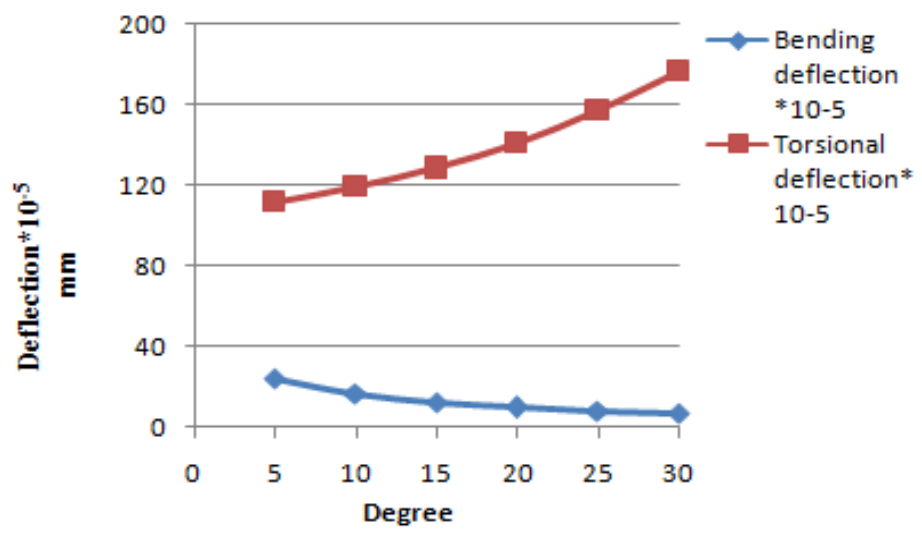

Fig. 6 Graph of deflection in mm versus $\Theta$ in degrees for a tapered SSF. 


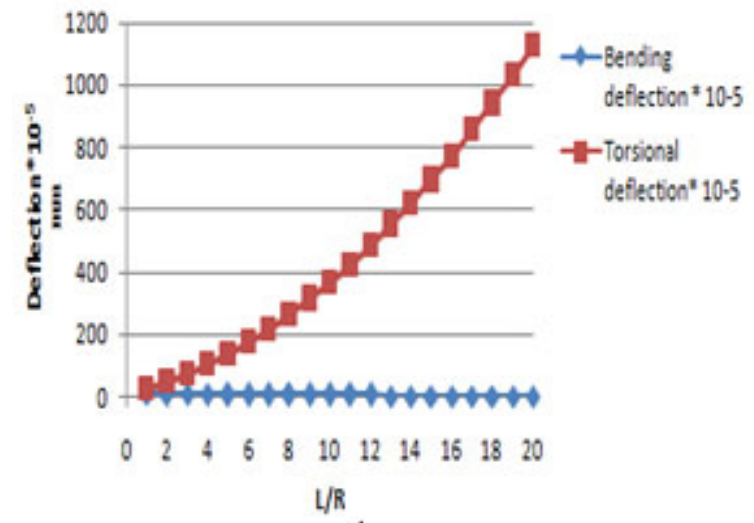

(a)

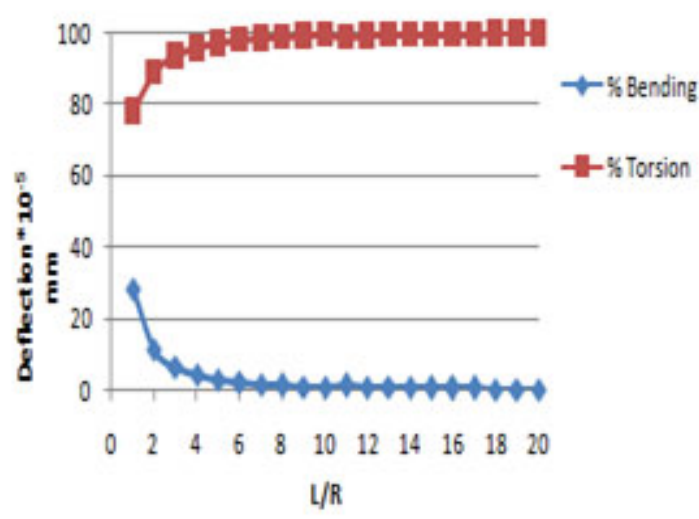

(b)

Fig. 7 (a) Different $L / R$ ratios versus deflection (b) percent deflection (\%) versus different $L / R$ ratios for a tapered SSF.

After comparing the FEA results of the bending and the torsional deflection for cylindrical, elliptical and tapered SSFs, it was found that the tapered SSF has much smaller bending deflection than the elliptical and the cylindrical support, as shown in Fig (8). The tapered SSF has smaller torsional deflection than the elliptical support and greater than the cylindrical support, but still it is extremely small, as shown in Table. 2. Thus, the study recommends the tapered shape support to be used for the part with thin ends.

Table 2 Results of the bending and the torsional deflection for different shapes of SSFs with an $L / R$ ratio of 6 .

\begin{tabular}{|c|c|c|}
\hline Shape of SSF & Bending deflection $/ \mathrm{mm}$ & Torsional deflection $/ \mathrm{mm}$ \\
\hline Cylindrical & 0.00040926 & 0.0010936 \\
\hline Elliptical & 0.0017381 & 0.0055245 \\
\hline Tapered & $6.56 \cdot 10^{-5}$ & 0.0015487 \\
\hline
\end{tabular}

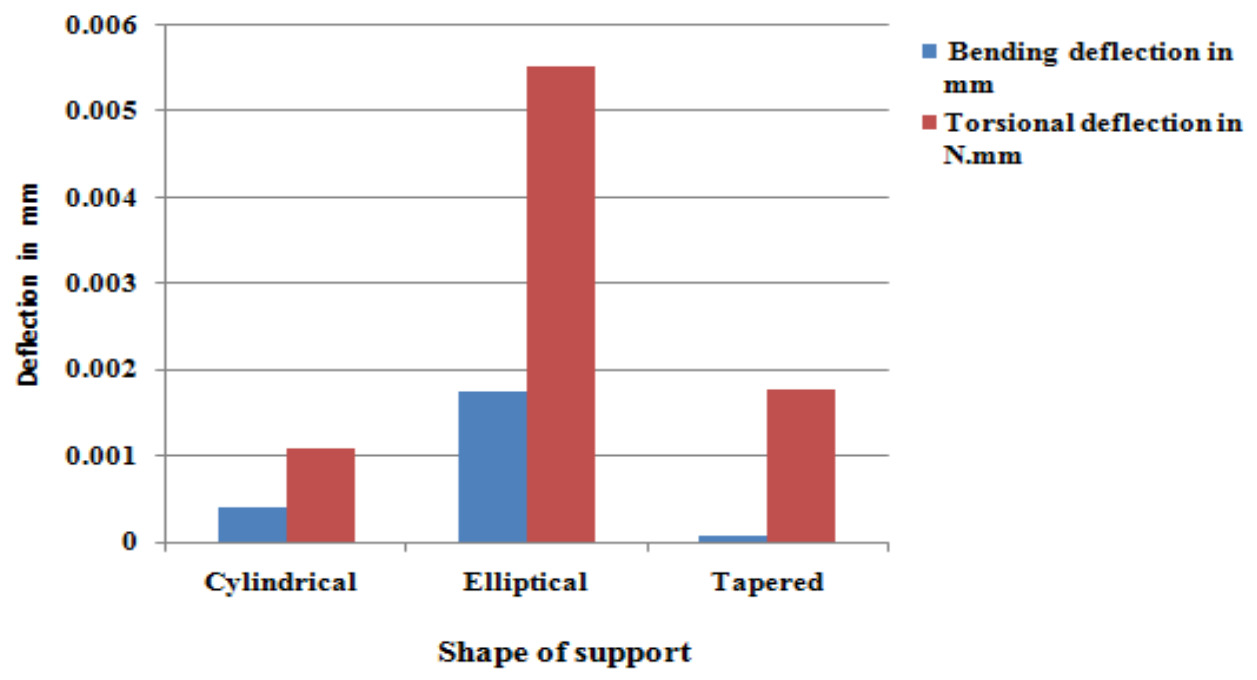

Fig. 8 Comparison of the bending and the torsional deflection for $L / R=6$ for different shapes.

4.3 Relation between the part and the size of a sacrificial support

The size of the SSF will depend upon the diameter of the part for which it is created [7]. The diameter of the part used is a measure for calculating the diameter of the support. In the current approach in which the part is considered as a fixed end beam model, the length and 
the diameter of the support vary according to the part diameter and there is a linear relationship between the support diameter, the support length, and the part diameter, as shown in Fig. 9 (a) and (b). Using the finite element analysis, a number of iterations for the part diameter are done by varying the support diameter and by keeping the part diameter fixed such that the deflection produced in the part is within the allowable limit. Results of the FEA for the diameter and the length of the support for different diameters of the part having a deflection within the specified range are shown in Fig (9a) and Fig (9b).

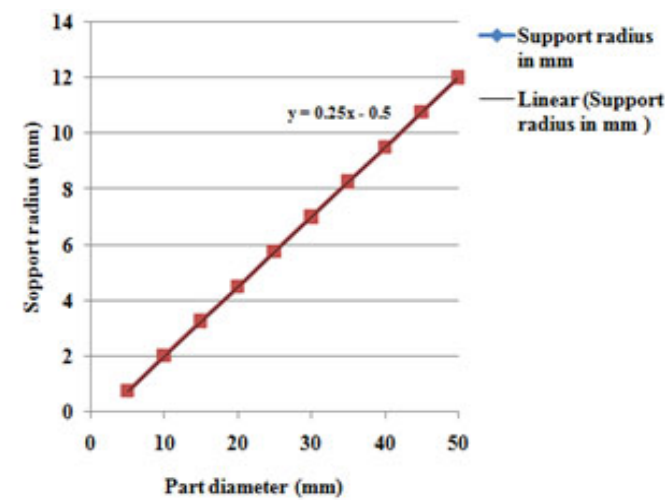

(a)

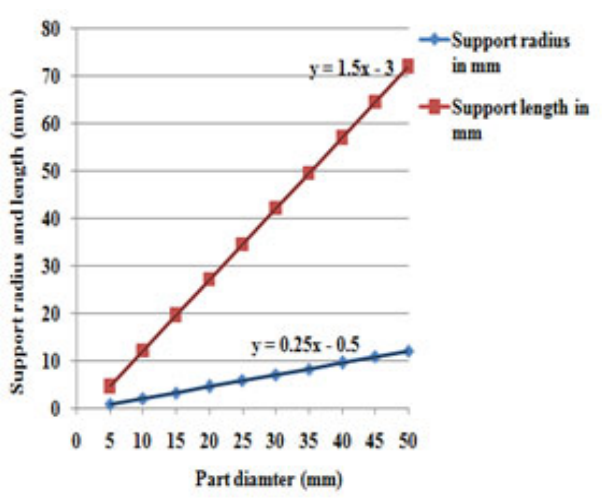

(b)

Fig. 9 (a) Part diameter versus support radius (b) Part diameter versus support diameter and support length (c) support radius versus support length.

\subsection{Location of a support}

Supports are located at the centre point of the part end such that they are at a " $T$ " distance apart from the outer boundary of the part, as shown in Fig. (10a) - (10c). Equations (3) - (5) show the formulas for finding the moment arm $T$ for the circular, elliptical, and tapered shapes of SSFs, respectively. Thus, a support to be created should be at the $T$ distance apart from the outer boundary of the part and should be located at the centre of the part end. $R$ represents the radius of the part in (mm); $r$ is the radius of the support in (mm), and $T$ is the moment arm in (mm).

Circular SSF: $T=R-r$

Elliptical SSF: $T=R-r$

Tapered SSF: $T=R-r$

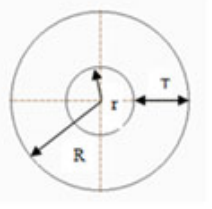

F.V|

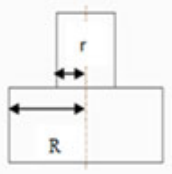

T.V.

Circular SSF

(a)

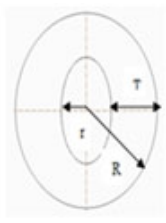

F.V

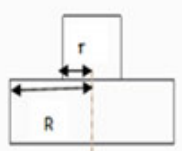

T.V.

Elliptical SSF

(b)

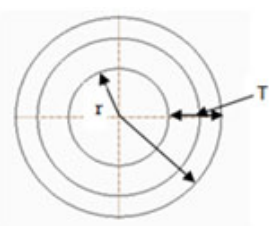

F.V.

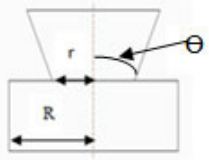

T.V.

Tapered SSF

(c)

Fig. 10 SSF shapes used in the determination of the moment arm T: (a) circular (b) elliptical, and (c) tapered. 


\subsection{Number of supports}

An even or an odd number of supports can be used on each side of the part. The maximum number of supports used on each side of the part is 2 . The temporary support is longer than the permanent support. The permanent support is designed to provide stiffness to the part during machining while the temporary support is used to give support to the part and to the permanent support. The supports can be provided in ratios of 1:1, 2:2, and 2:1, respectively, as shown in Fig. 11 (a) - 11(c). A maximum of one temporary support and one permanent support is provided on each side of the part [7].

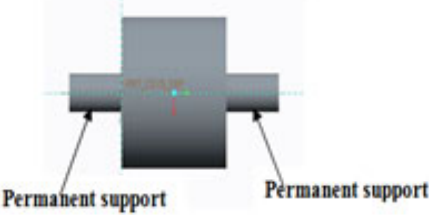

(a)

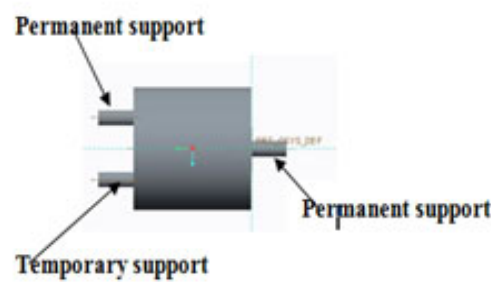

(b)

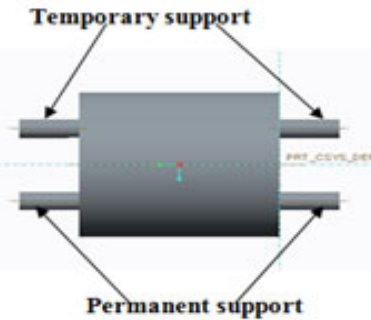

(c)

Fig. 11 The number of supports to the part in the ratios: (a) 1:1 (b) 2:1 (c) 2:2.

\section{Validation of the design parameters intended for a part with thin ends - a case study of the hip joint}

A hip joint part shown in Fig.12 (a-c) will be used for illustrating the steps in the SSF design. The applicability of the designed SSF to the 4 axis CNC machining for the part with thin ends will be checked using FEA. The length, width, and thickness of the square bar of aluminium material are $172 \mathrm{~mm}, 89 \mathrm{~mm}$, and $17 \mathrm{~mm}$, respectively; the calculated diameter and length of the permanent cylindrical support are $5.4 \mathrm{~mm}$ and $16.2 \mathrm{~mm}$, respectively; the diameter and length of the temporary cylindrical support are $8.25 \mathrm{~mm}$ and $51.25 \mathrm{~mm}$; the diameter of the tapered support (with the taper of 30 degree) at the small contact end is calculated as $3.496 \mathrm{~mm}$ and at the rear contact end as $9.54 \mathrm{~mm}$; the length of the support is $10.47 \mathrm{~mm}$. The dimensions of the finished hip joint part after the CNC-RP machining are $149.95 \mathrm{~mm} * 47.089 \mathrm{~mm} * 16.68 \mathrm{~mm}$.

Supports are created automatically at the centre of ends of the parts by implementing the designed methodology using $\mathbf{C}++$ and are connected to the Master CAM software for creating the $\mathrm{G}$ code for $\mathrm{CNC}$ machining $[33,34]$. For the CNC-RP process, the supports are created automatically at the ends of the part to create the fixture process plans for a rapid machining process. In the CNC-RP process, the machining of the part along with the support is divided into three sections which are given below:

\section{Left support section}

\section{Part section}

\section{Right support section}

Thus, during the machining process, the left support section is created first, then the part section is machined by simultaneous milling and turning, and then the right support section is machined to give support to the part during machining. After the machining process has been completed, the part with supports attached to it is created; temporary supports are removed by sawing or machining, and the finishing of the part is done at that end. Finally, the finished part is ready for use. Before starting the practical machining of the part with SSFs, the failure 
mode checking is required to find whether the designed SSF intended for the part with thin ends is suitable. For that purpose, FEA is done using the Ansys 14.0 software to check the deflection and the normal stresses produced in the part; the deflection should be at/below a permissible limit of $0.025 \mathrm{~mm}$ [7]. During FEA, the thick end of the part is fixed to the indexer by a support and the thin end of the part is fixed to the tailstock by a tapered support. The arrangement of the part fixed at both ends using SSFs is considered as a fixed end beam model. A mesh size of $1.6 \mathrm{~mm}$ is used for the meshing of the part. A force of $22 \mathrm{~N}$ is applied at the middle of the part assumed as a fixed end beam model [37].

Three different combinations of sacrificial support structures are created and designed for the machining of a hip joint part with thin ends, as shown in Fig. 12 (a-c). Static structural analysis of the three combinations was done to check the permissible deflection and the normal stresses produced in it. The combination of SSFs giving the minimum values of deflection and normal stresses are the desired design.

1. Hip joint with cylindrical and tapered supports.

2. Hip joint with cylindrical and elliptical supports.

3. Hip joint with cylindrical supports.

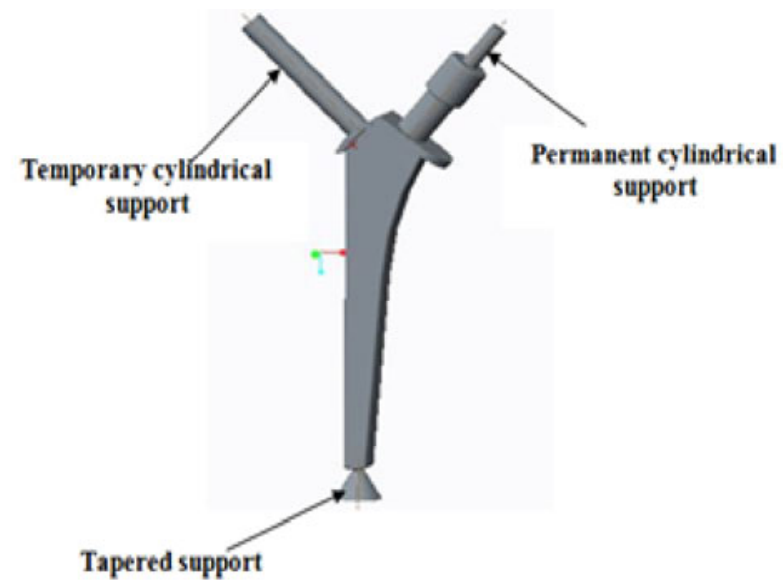

(a)

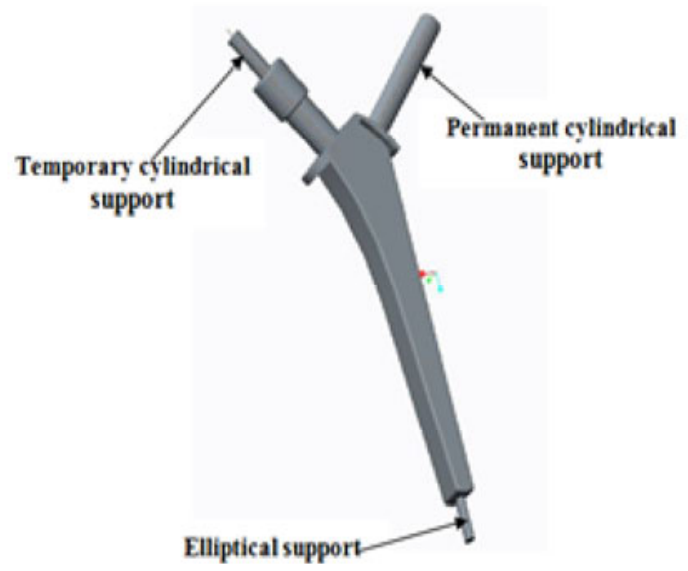

(b)

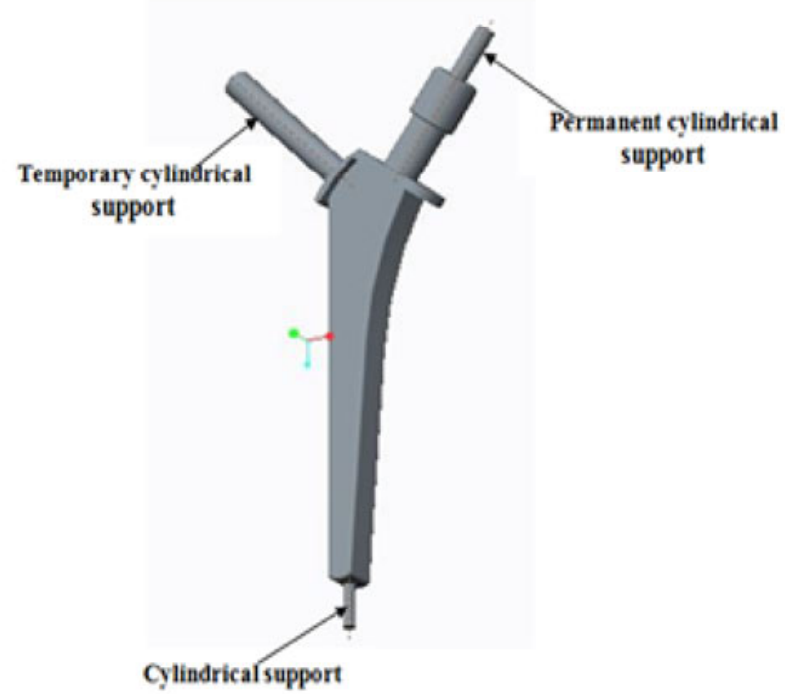

(c)

Fig. 12 Hip joint parts with (a) cylindrical and tapered supports (b) cylindrical and elliptical supports (c) three cylindrical supports. 
5.1 Finite element analysis to check the deflection and the normal stresses produced in a hip joint with different combinations of designed sacrificial support structures.

Meshing of a part with SSFs is done with a mesh of $1.6 \mathrm{~mm}$. The maximum total deflection and the maximum normal stresses produced in the part are calculated using FEA with the Ansys 14 software, as shown in Fig. 13 (a-c) and Fig.14 (a-c), respectively. Values of the maximum total deflection produced in the hip joint part with the combination of cylindrical and tapered supports, with that of cylindrical and elliptical supports, and with all cylindrical supports are $0.0012728 \mathrm{~mm}, 0.001934 \mathrm{~mm}$, and $0.0016363 \mathrm{~mm}$, respectively, as shown in Fig. 13 (a-c). Maximum normal stresses produced in the hip joint part with the combination of cylindrical and tapered supports, with that of cylindrical and elliptical supports, and with all cylindrical supports are $4.1666 \mathrm{MPa}, 6.5233 \mathrm{Mpa}$, and $4.8763 \mathrm{MPa}$, respectively, as shown in Fig. 14 (a-c).

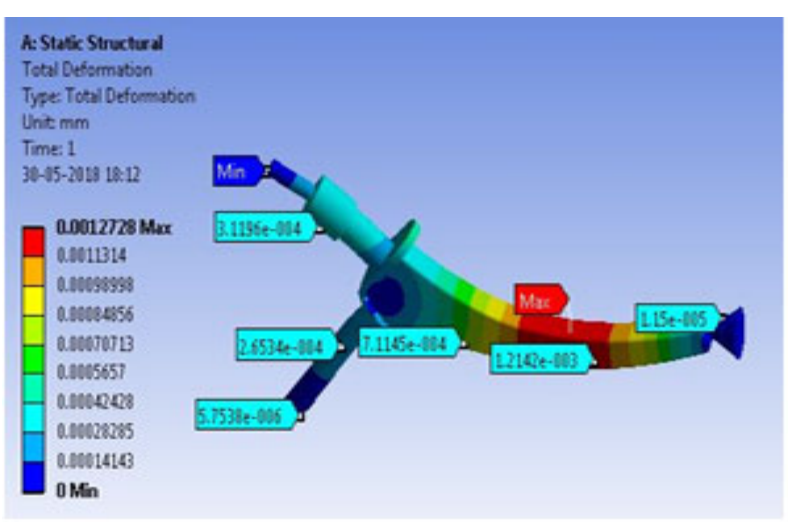

(a)

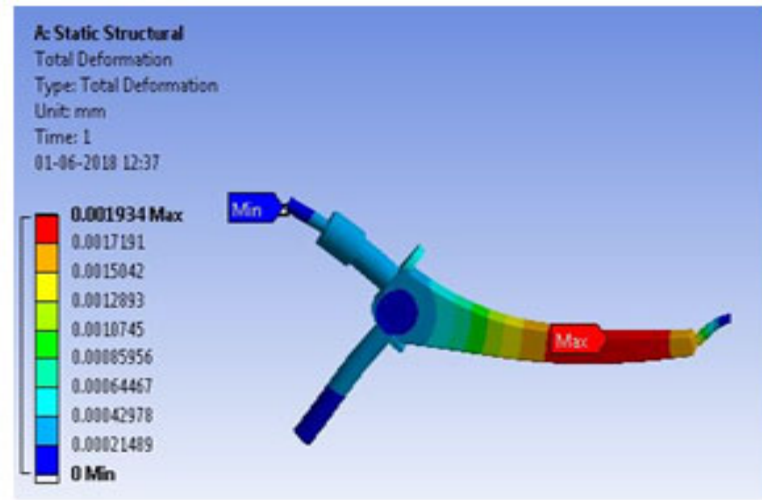

(b)

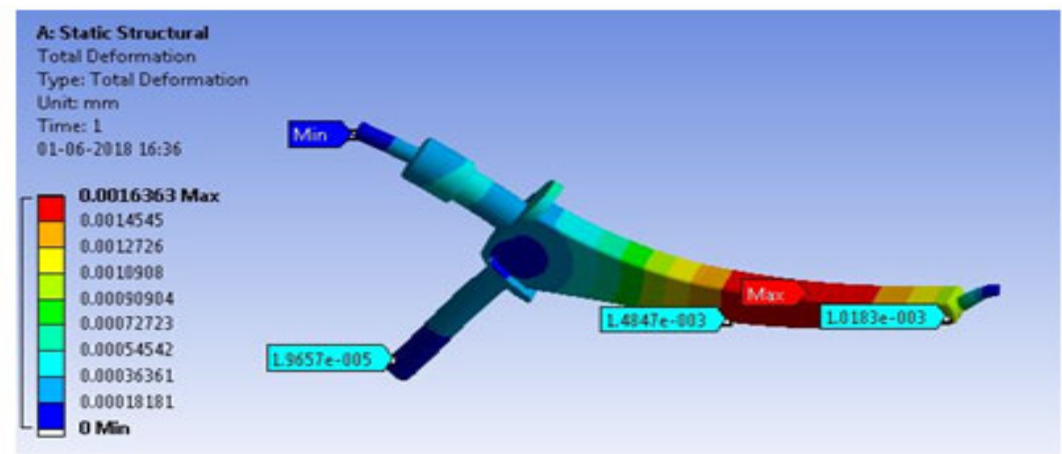

(c)

Fig. 13 Results of FEA for maximum deflection produced in a hip joint part (a) with cylindrical and tapered supports (b) with cylindrical and elliptical supports (c) with all cylindrical supports. 


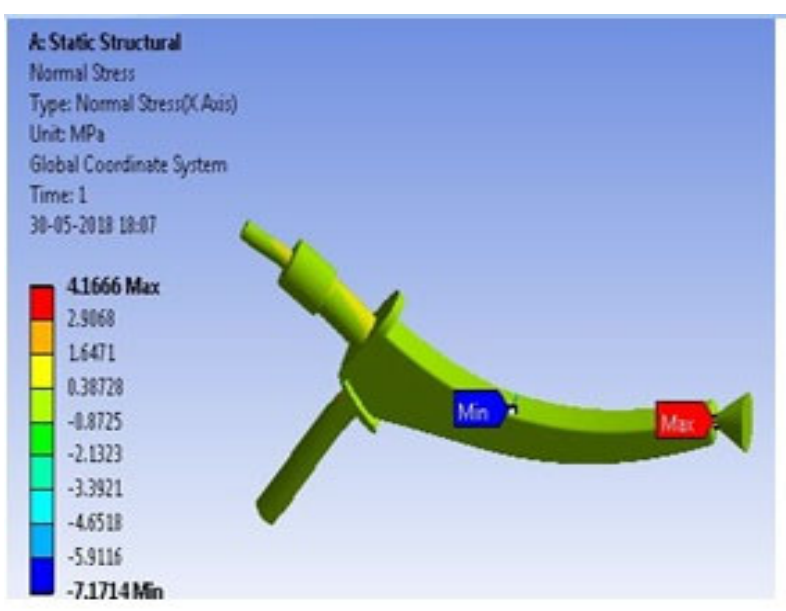

(a)

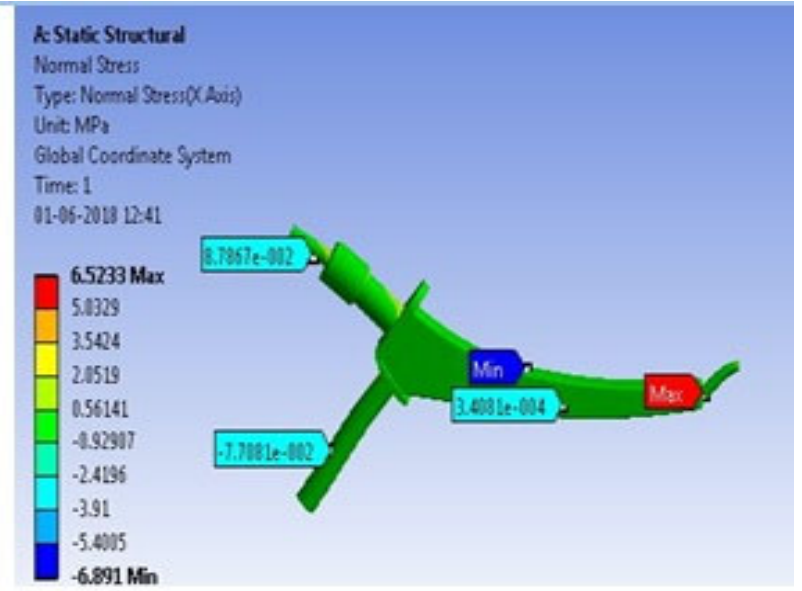

(b)

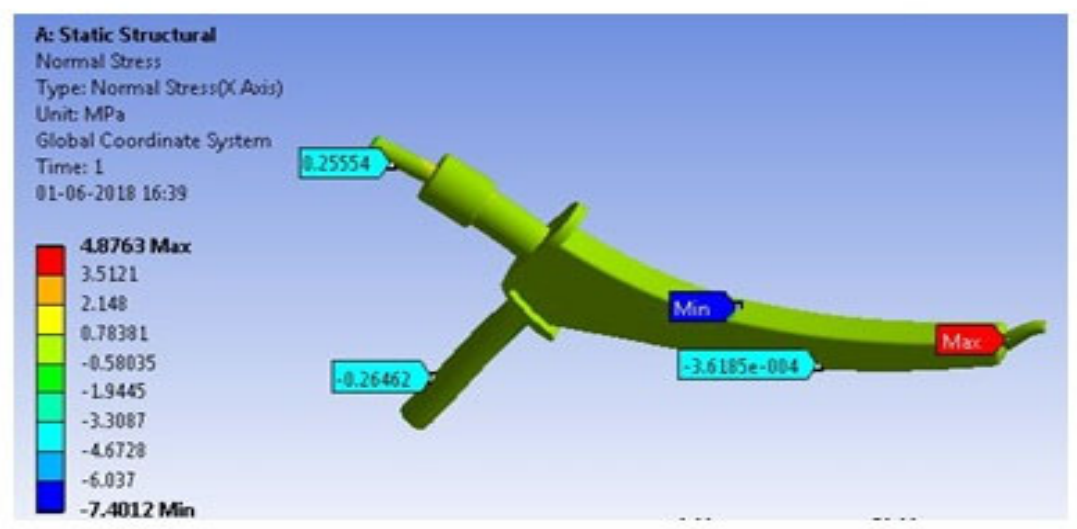

(c)

Fig. 14 Results of FEA for maximum normal stresses produced in a hip joint part (a) with cylindrical and tapered supports (b) with cylindrical and elliptical supports (c) with all cylindrical supports.

\subsection{Results and discussions of the designed sacrificial support structure}

The tapered support is best suited for the CNC-RP machining of an intricate part with thin ends as the deflection produced in the part is less than or equal to the permissible limit of $0.025 \mathrm{~mm}$ [7]. The design of a cylindrical support for a part with thick ends, which is parallel to the axis of rotation of the part, was developed and the issue of the design of the SSF for an intricate part with thin ends was discussed in the research work presented in [7]. Elliptical and tapered SSFs are best suited for the CNC-RP machining of intricate parts with thin ends. The $L / R$ ratio for the cylindrical, elliptical, and tapered permanent supports designed for the CNCRP machining of parts with thin ends is 6 as the bending deflection is smaller than the torsional deflection up to the length to radius ratio of 6 .

For the tapered support, the bending deflection is negligible and only the torsional deflection occurs in the part, as shown in Fig. 8(a-b); as a result, the tapered supports are best suited for the CNC-RP machining of intricate parts with thin ends. For temporary cylindrical, elliptical and tapered supports, it is suggested to use an $L / R$ ratio of 12 . The result obtained for the $L / R$ ratio for the cylindrical support is validated by comparing it with the results obtained in the previous study on automated fixture design for rapid machining [7]. A maximum of two supports can be used on each side of the part, out of which one is temporary and the other is permanent, as discussed in section 4.5. The machining sequence in the automated fixture design for rapid machining processes was studied by Boonsuk and Frank [7]. In their research 
work, the authors used the same methodology in the CNC-RP machining of the part. The case study of the hip joint part is used to check the feasibility and the robustness of the designed SSF intended for a part with thin ends. The FEA results of different combinations of SSFs show that the deflection and the normal stresses produced in the part are lowest when a combination of cylindrical and tapered supports is used. The deflection and the normal stresses produced in the part are highest when a combination of cylindrical and elliptical supports is used, as shown in Fig 15. A combination of cylindrical and tapered SSFs is best suited for a part with thin ends as the deflection produced in the part, according to FEA results, is $1.2728 \cdot 10^{-3} \mathrm{~mm}$, which is less than $0.025 \mathrm{~mm} \mathrm{[7],} \mathrm{and} \mathrm{the} \mathrm{normal} \mathrm{stress}$ corresponding to that deflection value is $4.166 \mathrm{MPa}$, as shown in Table 3.

Table 3 Results of the total deflection and the normal stress in a hip joint part with different supports attached to it.

\begin{tabular}{|c|c|c|}
\hline $\begin{array}{c}\text { Hip joint with different } \\
\text { SSFs }\end{array}$ & $\begin{array}{c}\text { Total deflection } \\
\cdot 10^{-3} \mathrm{~mm}\end{array}$ & $\begin{array}{c}\text { Normal stress } \\
\mathrm{MPa}\end{array}$ \\
\hline $\begin{array}{c}\text { Hip join with cylindrical } \\
\text { and tapered SSFs }\end{array}$ & 1.2728 & 4.166 \\
\hline $\begin{array}{c}\text { Hip join with cylindrical } \\
\text { and elliptical SSFs }\end{array}$ & 1.934 & 6.5233 \\
\hline $\begin{array}{c}\text { Hip joint with all } \\
\text { cylindrical SSFs }\end{array}$ & 1.6363 & 4.8763 \\
\hline
\end{tabular}

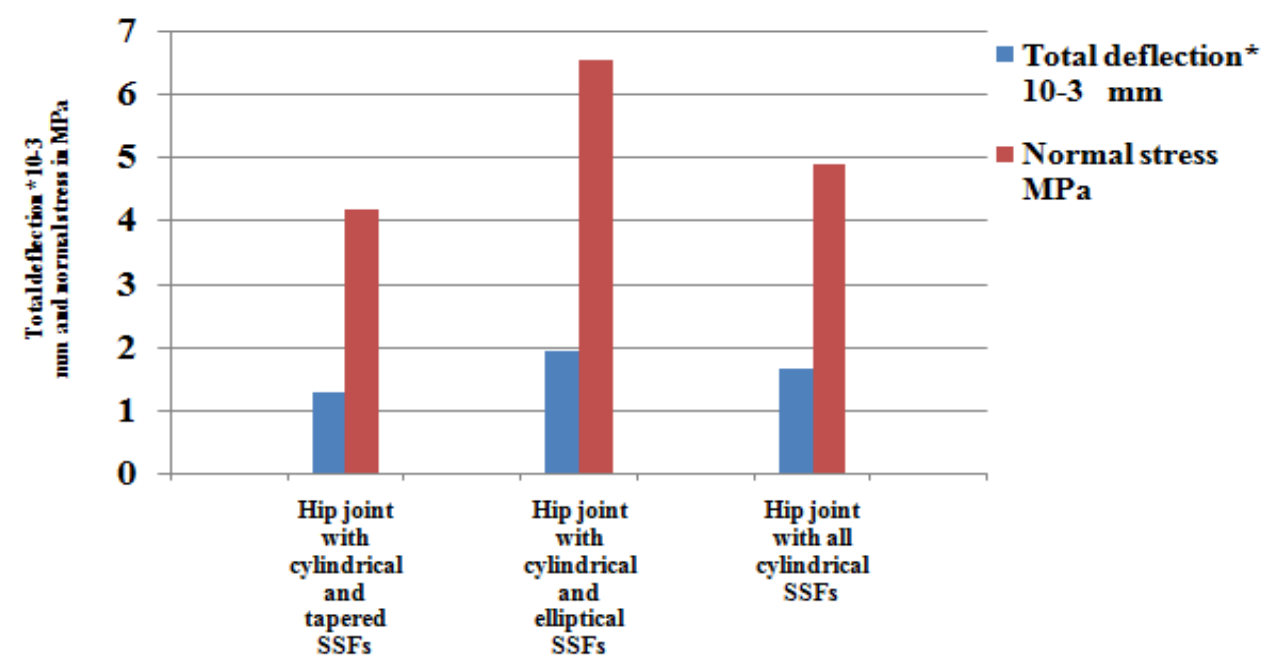

Hip joint with different shapes of SSFs

Fig.15 Maximum total deflection and maximum normal stress for different shapes of SSFs.

\section{Conclusions}

This paper presents a methodology for the design of SSFs intended for the CNC-RP machining of intricate parts with thin ends. The following conclusions are drawn according to the results obtained by FEA:

- Reduction in the maximum bending deflection and the maximum torsional deflection is noted in the tapered SSF compared to the cylindrical and elliptical SSFs. The accurate CNC-RP machining of the part will depend upon the robust design parameters of the SSF. The design of the SSF should be such that it should not allow 
the part to bend or deflect during the CNC-RP machining. The SSF designed in this paper allows the machining of a part with thin ends with minimum allowable deflection and normal stresses produced in it during the CNC-RP machining.

- The FEA analysis results showed that a combination of cylindrical and tapered SSFs is best suited for the machining of an intricate part having thin ends because it gives less total deflection and lower normal stresses produced in the part during the CNC-RP machining.

- The tapered SSF is best suited for holding and giving support to a vast array of intricate parts having thin ends during the CNC-RP machining.

- The CNC-RP machining of a vast array of intricate parts having thin ends is made possible by replacing a traditional setup of fixing devices such as vises, clams, and vblocks with designed SSFs.

- Reduction in the time required for the fixture planning and fabrication with respect to traditional fixing methods is achieved by using the designed SSF for the CNC-RP machining.

FUNDING: This research did not receive any specific grant from funding agencies in the public, commercial, or not-for-profit sectors.

\section{REFERENCES}

[1] Frank, C. M., Wysk R., Joshi, B., 2004, "Rapid planning for CNC machining -a new approach to rapid prototyping", Journal of Manufacturing Systems, 3(3), p. 242-255. https://doi.org/10.1016/s0278-6125(04)80037-2

[2] Katherine, F., Maria, Y., Kristin, W., 2016, "Design Principles: Literature Review, Analysis, and Future Directions," Journal of Mechanical Design, 138 (10), p. 1-13.

[3] Osman, Z., Case, K., Watts, D., 2017, "Rapid Process Planning in CNC Machining for Rapid Manufacturing Applications," International Journal of Mechanical Engineering and Robotics Research, 6(2), p.118-121. https://doi.org/10.18178/ijmerr.6.2.118-121

[4] Frank, C. M., Joshi, B., Wysk, R., 2002, "CNC-RP: A technique for using CNC machining as a rapid prototyping tool in product/process development," In Proceedings of the Industrial Engineering Research Conference, Orlando, FL. Citeseer. https://doi.org/10.1115/detc2003/dfm-48157

[5] Sambu, S., Chen, Y., and Rosen, D. W., 2004, "Geometric Tailoring: A Design for Manufacturing Method for Rapid Prototyping and Rapid Tooling,” Journal of Mechanical Design, 126(4), p. 571. https://doi.org/10.1115/1.1758250

[6] Maniara, P., Vakhariab, P., 2014, "Design \& development of rotary fixture for CNC with computer aided mass balancing method as premortem tool," 2nd International Conference on Innovations in Automation and Mechatronics Engineering, ICIAME, Procedia Technology 14: 397 - 404. https://doi.org/10.1016/j.protcy.2014.08.051

[7] Boonsuk, W., Frank, M. C., 2009, “Automated fixture design for a rapid machining process," Rapid Prototyping Journal, 15(2), p. 111-125. https://doi.org/10.1108/13552540910943414

[8] Petrzelka, J., Matthew, C.F., 2009, "Advanced process planning for subtractive rapid prototyping," Proceedings of Industrial and Manufacturing Systems Engineering Conference and Posters, Iowa State University Digital Repository.

[9] Frank, C. M., Wysk, R., Joshi, B., 2006, "Determining setup orientation from the visibility of slice geometry for rapid CNC machining," Journal of Manufacturing Science and Engineering ASME, 128 (1), p.228-238. https://doi.org/10.1115/1.2039100

[10] Radhakrishnan, R., and McAdams, D. A., 2005, “A Methodology for Model Selection in Engineering Design,” Journal of Mechanical Design, 127(3), p. 378. https://doi.org/10.1115/1.1830048

[11] Wang, Y., Arabnejad Khanoki, S., Tanzer, M., and Pasini, D., 2018, "Hip Implant Design with ThreeDimensional Porous Architecture of Optimized Graded Density," Journal of Mechanical Design,140 (11),p. 1-51. https://doi.org/10.1115/1.4041208 
[12] Kevin, B., Richard, W., Matthew, C. F., 2004, "Economics of sacrificial fixturing for CNC machining and rapid manufacturing," Proceedings of ASME Design Engineering Technical Conference, Salt Lake City, Utah, USA.

[13] Osman, Z., Case, K., Watts, D., 2014, "Cutting tools in finishing operations for CNC rapid manufacturing processes: experimental studies," International Journal of Aerospace and Mechanical Engineering, 8(6). p.1108-1112.

[14] Suresh Kumar, R., Alexis, J., Thangarasu, S., 2017, “Optimization of high speed CNC end milling process of BSL 168 Aluminium composite for aeronautical applications," Transaction of Canadian Society of Mechanical Engineering, 41(4), p. 609-625. https://doi.org/10.1139/tcsme-2017-1043

[15] Tong, Qu., Amir, K., Der, L., Behdinan, K., 2003, "Finite element modelling and stability analysis of chatter in end milling machining," Transaction of Canadian Society of Mechanical Engineering, 27(3), p. 205-221. https://doi.org/10.1139/tcsme-2003-0012

[16] Osman, Z., Case, K., Darren, W., 2015, "End mill tools integration in CNC machining for rapid manufacturing processes: simulation studies," Production \& Manufacturing Research, 3(1), p. 274-288. https://doi.org/10.1080/21693277.2015.1094756

[17] Frank, M., 2007, "Implementing Rapid Prototyping Using CNC Machining (CNC-RP) Through a CAD/CAM Interface," Proceeding of Solid Freeform Fabrication, pp. 112-123.

[18] Frank, M., Joshi, A., and Anderson, D., 2010, "Patient-Specific Bone Implants Using Subtractive Rapid Prototyping," PhD thesis, pp. 854-863.

[19] Najlaoui, B., Nejlaoui, M., Affi, Z., Romdhane, L., "Mechatronic design optimization of the mechanism in a sewing machine", Proceeding of Institution of Mechanical Engineering Part C: Journal of Mechanical Engineering Science, 0(0), p. 1-15.

[20] Mohammad, J. L., Omid, Rahmani., "Bending analysis of sandwich plates with composite face sheets and compliance functionally graded syntactic foam core," Proceeding of Institution of Mechanical Engineering Part C: Journal of Mechanical Engineering Science, 0(0), p. 1-25. https://doi.org/10.1177/0954406215616417

[21] Zhong, L., You, W., Yunpeng, Z., Xueyan, Z., Deyou, W., "The similitude design method of thin-walled annular plates and determination of structural size intervals," Proceeding of Institution of Mechanical Engineering Part C: Journal of Mechanical Engineering Science, 0(0), p. 1-11. https://doi.org/10.1177/0954406215592055

[22] Honggen, Z., Shan, L., Guochao, L., Guizhong, T., Ziyu, W., Chuhui, Wang., 2018, "Machining Stress Analysis and Deformation Prediction of Connecting Rod Based on FEM and GRNN," Iranian Journal of Science and Technology: Transaction of Mechanical Engineering, p.1-10.

[23] Pandilov, Z., Milecki, A., Nowak, A., Górski, F., Grajewski, D., Ciglar, D., Mulc, T., Klaić, M., 2015, "Virtual modeling and simulation of a CNC machine feed drive system", Transactions of FAMENA, 39(4), p.37-54.

[24] Wang, C.Y.,Chen, H. C., Lee, Y. B.,2012, "Design model for micro end mills made by using the finite element method", Transactions of FAMENA, 36(2), p.41-50.

[25] Sustarsic, B., Leskovšek,V., 2010, "FEM simulation of the design optimization of a hot forging die and its heat treatment", Transactions of FAMENA, 34(2), p.1-12.

[26] Mar, R., Bouazara, M., Khadir, L., Cai, G., 2011, "Structural optimization algorithm for vehicle suspension”,Transaction of Canadian Society of Mechanical Engineering, 35(1), p. 1-17. https://doi.org/10.1139/tcsme-2011-0001

[27] Kuo, L., Cleghorn, W., 2006, "Stress based finite element method for Euler Bernoulli beams," Transaction of Canadian Society of Mechanical Engineering, 3D (1), p.1-6. https://doi.org/10.1139/tcsme-2006-0001

[28] Urbanic, R. J., and ElMaraghy, W. H., 2009, "Using a Modified Failure Modes and Effects Analysis Within the Structured Design Recovery Framework,” Journal of Mechanical Design, 131(11), p. 111005. https://doi.org/10.1115/1.3201968

[29] Ramteke, M.A., Ashtankar, M.K., 2018, "Finite element analysis study for machining parameters using CNC-RP machining of hip joint part with innovative sacrificial support structure as a fixture", Journal of Engineering Technology,6(IOT), p.337-359.

[30] Scheider. R., 1997, "Start with the right speed and feeds," Available from: www.mmsonline.com/articles/019703.html. [Accessed March 2017]. 
[31] Nur, R., Noordin, M ., Izman, S., Kurniawan, D., 2015, "Machining parameters effect in dry turning of AISI 316L stainless steel using coated carbide tools," Proceeding of Institution of Mechanical Engineering Part E: Journal of Processing of Mechanical Engineering, 0(0) , p.1-8. https://doi.org/10.1177/0954408915624861

[32] Robertson, B.F., Walther,J., and Radcliff,D. F., 2007, "Creativity and the Use of CAD Tools: Lessons for Engineering Design Education From Industry,” Journal of Mechanical Design, 129(7), p. 753. https://doi.org/10.1115/1.2722329

[33] Joardar, C., Notash, L., 2004, "CAD data extraction for simulation: an application in camera view modelling," Transaction of Canadian Society of Mechanical Engineering, 28(2A), p. 153-163. https://doi.org/10.1139/tcsme-2004-0012

[34] Frank, C.M., Wysk, R., Joshi, B., 2003, "Rapid prototyping using CNC machining. In proceedings of the ASME Design Engineering Technical Conferences and Computers and Information in Engineering Conference," Chicago, Illinois, USA. https://doi.org/10.1115/detc2003/dfm-48157

[35] Citing online sources: Available from https://www.nandishwarsteel.com/stainless-steel-317-3171-sheetsplates.html [accessed May 2018].

[36] Đelošević, M., Vukajlov, L., Tepić, G., Milinković, A., Brkljač, D., 2018, "Design of columns in terms of stability", Transactions of FAMENA, 42(3), p.39-50. https://doi.org/10.21278/tof.42204

[37] Spitler, D., Lantrip, J., Nee, J., Smith, A., 2003, "Fundamentals of the tool design, Society of Manufacturing Engineering," Dearborn, MI.

Submitted: $\quad 26.9 .2018$

Accepted: $\quad 26.4 .2019$
Ashwini M. Ramteke ashiwiniramteke332@gmail.com Mechanical CAD/CAM Department, Visvesvaraya National Institute of Technology, Nagpur, India

Kishor. M. Ashtankar kmashtankar@mec.vnit.ac.in Mechanical Department, Visvesvaraya Nation Institute of Technology, Nagpur, India 